\title{
Characteristics of a nozzle spray in relation to its application to aeroponics
}

\author{
Tejas Narasegowda ${ }^{1}$ and Navneet Kumar ${ }^{2}$ \\ ${ }^{1}$ University Visvesvaraya College of Engineering \\ ${ }^{2}$ Indian Institute of Science
}

May 5, 2020

\begin{abstract}
Aeroponics or Soil-less agriculture is a relatively new and recent type of practice, where plants are grown without soil while nutrient-rich water is provided via an atomized spray system to the suspended roots. Spray nozzles are easy-to-use in supplying water (and fertilizers) to (mainly) the roots and root hairs of the desired crop (or plant) for production. We characterize a spray nozzle delivering water vertically above against the gravity by measuring, experimentally, its (a) spray drift, (b) spray height, (c) maximum spray angle, (d) spray width, and (e) droplets sizes. Experiments were carried out at different inlet pressures and a majority of the above mentioned parameters were obtained by processing the images captured using digital (or high speed) camera, sometimes along a plane lighted by a high-power laser source. We also studied the spray (or jet) behaviour at different vertical heights and different horizontal planes using a unique polythene sponge method. We studied the mass flow rate, the mass of water absorbed, and droplet size dynamics (as a function of time and pressure) using this method. A mathematical model is proposed to understand such flows, whose results matched reasonably well with the experimental values. We believe that this study can be extrapolated to other nozzles (or sprays) to obtain similar characteristic parameters. A study was conducted on the characterization of "Plant-water uptake". This study hence is critical in selecting the desired spray system for a given canopy. The research conducted here would be crucial in designing an Aeroponic system in a controlled agricultural environment.
\end{abstract}

\section{Hosted file}

Manuscript - Engineering reports.pdf available at https://authorea.com/users/293364/articles/ 421317-characteristics-of-a-nozzle-spray-in-relation-to-its-application-to-aeroponics 


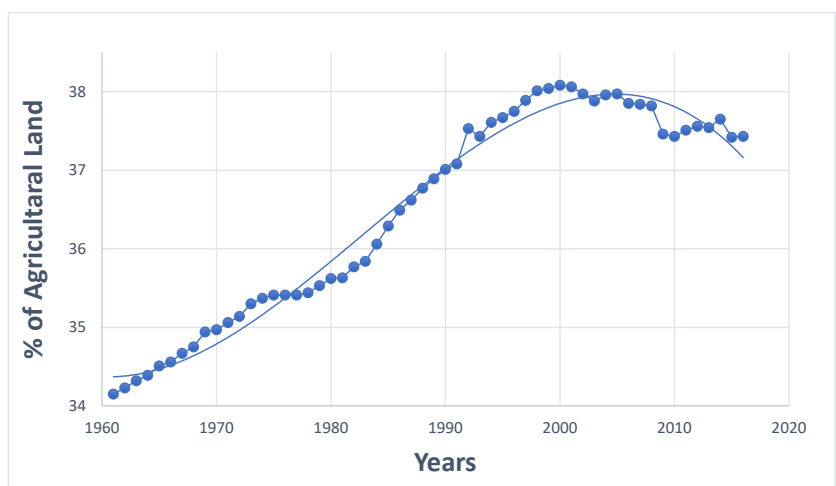

Figure 1 Plot showing annual relative agricultural land in the world [2]

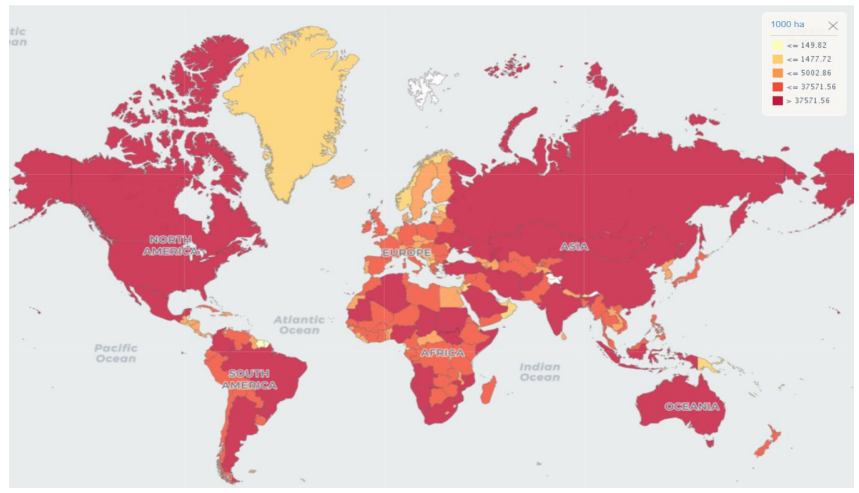

Figure 2 World map showing the relative distribution of agricultural land [2]. 